\title{
Pengaruh Logistics Service Quality Terhadap Customer Satisfaction dan Customer Loyalty Pada Industri Ritel di Indonesia
}

\author{
Adi Prasetyo Tedjakusuma ${ }^{1 *}$, Auliya Delananda ${ }^{1}$, Erna Andajani ${ }^{1}$ \\ ${ }^{1}$ Jurusan Manajemen, Fakultas Bisnis dan Ekonomika, Universitas Surabaya, Surabaya-Indonesia 60293 \\ *corresponding author: atedjakusuma@staff.ubaya.ac.id
}

Abstract-The service industry sector has great potential for increasing economic growth, in which this sector can contribute to improving national GDP, job creation, and poverty reduction. This study aims to determine and analyze the effect of Logistics Service Quality on Customer Satisfaction and Customer Loyalty at Matahari Department Store. Data processing was done using a quantitative approach and this type of research is causal research. The variables used in this study were logistics service quality, customer satisfaction, and customer loyalty. The data analysis technique used was Multiple Linear Regression using the SPSS 18.0 for window program. This study used a sample of respondents who have shopped online at Matahari Department Store at least once a year with a total sample of 200 respondents. The results of this study indicate the influence of Logistics Service Quality on Customer Satisfaction and Customer Loyalty at Matahari Department Store.

Keywords: Logistics service quality, customer satisfaction, customer loyalty

\begin{abstract}
Abstrak - Sektor industri jasa memiliki potensi besar untuk meningkatan pertumbuhan ekonomi dan dapat berkontribusi terhadap peningkatan PDB nasional, penciptaan lapangan kerja, dan pengurangan kemiskinan. Penelitian ini bertujuan untuk mengetahui dan menganalisis pengaruh Logistics Service Quality terhadap Customer Satisfaction dan Customer Loyalty pada Matahari Department Store. Pengolahan data dilakukan dengan menggunakan pendekatan kuantitatif dan jenis penelitian ini adalah penelitian kausal. Variabel yang digunakan dalam penelitian ini yaitu logistics service quality, customer satisfaction, dan customer loyalty. Teknis analisis data yang digunakan adalah Regresi Linear Berganda dengan menggunakan program SPSS 18.0 for window. Penelitian ini menggunakan sampel berupa responden yang pernah berbelanja online di Matahari Department Store minimal 1 kali dalam setahun dengan jumlah sampel yang digunakan dalam penelitian ini adalah 200 responden. Hasil penelitian ini menunjukkan adanya pengaruh Logistics Service Quality terhadap Customer Satisfaction dan Customer Loyalty pada Matahari Department Store.
\end{abstract}

Kata kunci: Logistics service quality, customer satisfaction, customer loyalty

\section{PENDAHULUAN}

Sektor industri jasa merupakan salah satu sektor ekonomi yang berkembang pesat di Indonesia dan memiliki potensi besar untuk meningkatan pertumbuhan ekonomi, dimana sektor ini dapat berkontribusi terhadap peningkatan PDB nasional, penciptaan lapangan kerja, dan pengurangan kemiskinan. Pertumbuhan sektor transportasi dan pergudangan diyakini akan terus berlanjut setelah pada kuartal I/2018 yang mencatatkan kenaikan sebesar $8,59 \%$ secara tahunan. Sementara itu, Badan Pusat Statistik (BPS) mencatat kedua sektor tersebut memberikan andil sebesar 0,35\% terhadap pertumbuhan ekonomi nasional sebesar 5,06\% pada kuartal I/2018. Pangsa sektor ini juga terus meningkat menjadi 5,41\% terhadap total PDB. Pada kuartal I/2018, sektor transportasi dan pergudangan berkontribusi $4,67 \%$ dari total produk domestik bruto (PDB) (Maulana \& Pradana, 2018).

Menurut World Bank (Bank Dunia), dalam Logistic Performance Index (LPI) 2018 Indonesia berhasil menduduki peringkat 46. Dua tahun sebelumnya, Indonesia hanya menempati posisi 63 dunia. LPI merupakan indeks kinerja logistik negara-negara di dunia yang dirilis oleh Bank Dunia per dua tahun sekali. Terdapat 160 negara yang masuk dalam penilaian tersebut dan didasarkan pada enam aspek yaitu, efisiensi customs \& border management clearance (bea cukai), kualitas infrastruktur perdagangan dan transportasi, kemudahan pengaturan pengiriman internasional, kompetensi dan kualitas jasa logistik, kemampuan melakukan tracking \& tracing, dan frekuensi pengiriman tepat waktu. Di tahun 2018, peringkat Indonesia meningkat ke posisi 46 dengan skor 3,15 atau naik 17 tingkat dari posisi 63 dengan 
skor 2,98 di tahun 2016. Dari semua aspek penilaian LPI 2018, aspek kepabeanan meraih skor terendah sebesar 2,67. Sementara itu, aspek penilaian tertinggi adalah ketepatan waktu dengan skor 3,67. Aspek lainnya yaitu infrastruktur dengan skor 2,89, pengiriman barang internasional 3,23, kualitas dan kompetensi logistik 3,1, dan pencarian barang sebesar 3,3 (Hidayat, 2018).

Demikian pula PDB sektor pergudangan, jasa penunjang angkutan, pos, dan kurir sepanjang 2017 juga menunjukkan pertumbuhan 14,3\% menjadi Rp 119,7 triliun dari sebelumnya (YoY). Sebagai informasi, kontribusi sektor logistik terhadap PDB nasional pada 2014 hanya mencapai 0,75\%, dan pada 2017 telah meningkat menjadi 0,88\% ("Belanja Online Marak...", 2018).

Terdapat beberapa perusahaan retail di Indonesia dalam kategori department store, yaitu PT. Matahari Department Store Tbk (Matahari Department Store) yang didirikan pada 24 Oktober 1958, PT. Mitra Adi Perkasa yang memiliki Sogo Department Store, yang dibuka pada 1990 di Jakarta, PT. Ramayana Lestari Sentosa Tbk (Ramayana Department Store) yang didirikan 1978, dan PT. Metropolitan Retailmart (Metro Department Store) yang didirikan 1991. Di antara empat perusahaan retail dalam kategori department store, dua di antaranya memiliki situs online, yaitu Matahari Department Store dan Sogo Department Store.

Awalnya, pihak Lippo Group telah membuka e-commerce yang bernama MatahariMall pada 9 September 2015, yang memiliki ratusan ribu pilihan produk dengan harga terbaik dari segala kebutuhan, mulai dari fashion wanita, fashion pria, kesehatan \& kecantikan, handphone dan tablet, laptop, gadget, elektronik, lifestyle, hobi, keperluan rumah tangga, dan lainnya. Tetapi, pada 9 November 2016 PT. Matahari Department Store Tbk (MDS) juga membuka ecommerce yang bernama MatahariStore, walaupun pada awalnya MDS telah memiliki halaman khusus di MatahariMall, hal ini dilakukan oleh pihak MDS karena pada situs MatahariStore hanya ingin berfokus pada fashion saja. Namun, pada saat pelanggan membuka situs web MatahariStore secara otomatis pelanggan juga langsung terhubung dengan MatahariMall karena alur transaksi pada MatahariStore akan ditangani langsung oleh MatahariMall.com, mulai dari konten, pembayaran, hingga pengiriman barang. MatahariMall.com memberikan fasilitas pelayanan yang terbaik untuk mendukung pelanggan dalam berbelanja online dengan aman dan terpercaya disertai dengan berbagai kemudahan untuk bertransaks, seperti transfer antar bank, kartu kredit dengan cicilan 0\%, COD dan sistem O2O (Online-to-Offline dan Offlineto-Online) (Bachdar, 2017).

Sementara itu, Sogo Department Store milik PT. Mitra Adi Perkasa saat ini juga telah memiliki e-commerce yang bernama MAPEMALL. Sebagai brand terkemuka, Sogo tak hanya menyediakan Sogo clothing dan aksesoris sogo untuk fashion para konsumennya, tapi juga beragam perlengkapan rumah yang akan meringankan aktivitas harian. Bahkan, terdapat penawaran menarik berupa voucher Sogo yang memungkinkan para pelanggan berbelanja produk Sogo lebih hemat. Order produk sogo melalui media online juga tersedia di MAPEMALL. Tak hanya itu, metode pembayaran di MAPEMALL juga sangat mudah melalui transfer bank, BCA Klikpay, atau kartu kredit. Para pelanggan juga bisa melakukan pembayaran langsung di tempat dengan sistem COD (Cash On Delivery) yang tentunya semakin memudahkan para konsumen untuk mendapatkan produk yang asli dan berkualitas tinggi.

Dari dua situs online department store tersebut yaitu MDS dan Sogo, Matahari Department Store yang menggunakan sistem 020 memiliki keunggulan dalam sistem pembayaran dan pengambilan barang. $\mathrm{O} 2 \mathrm{O}$ adalah layanan yang membuat customer mampu secara fisik membayar dan kemudian mengambil produk yang telah mereka pesan online sebelumnya. Customer juga dapat melakukan pembayaran serta pengambilan barang di: (1) Matahari Department Store pilihan customer, (2) Kiosk O2O (Instan Pick Up), (3)E-locker, (4) POS Restan, (5) Indomaret Pick Up Point, dan (6) E-Store.

Penelitian yang dilakukan Bouzaabia, Bouzaabia, dan Alexandru (2013) di Rumania dan Tunisian meneliti tentang pengaruh logistics service quality terhadap customer satisfaction dan customer loyalty dan objek yang dibahas pada penelitian tersebut merupakan salah satu retail 
yang ada di dua negara itu, yaitu Carrefour. Bouzaabia et al. menyarankan untuk melakukan penelitian yang sama, yaitu tentang pengaruh logistics service quality terhadap customer satisfaction dan customer loyalty di negara yang memiliki lingkungan budaya, sosial dan ekonomi yang berbeda. Oleh karenanya, penulis terdorong untuk melakukan penelitian tentang pengaruh logistics service quality terhadap customer satisfaction dan customer loyalty pada objek Matahari Department Store yang berada di Indonesia karena Matahari Department Store ini memiliki customer dari lingkup budaya, sosial dan ekonomi yang berbeda.

Konsep yang digunakan untuk Logistics Service Quality menurut Bienstock, Mentzer, dan Bird (1997), serta Mentzer, Flint, dan Hult (2001) logistik memainkan peran strategis dalam keberhasilan toko ritel. Mereka tidak lagi dianggap sebagai kegiatan operasional semata, melainkan sebagai variabel strategis yang merupakan faktor penting untuk kepuasan dan kesetiaan konsumen (Gil-Saura \& Ruiz-Molina, 2011).

Konsep Customer Satisfaction menggunakan definisi Kotler dan Keller 2016 yakni bahwa kepuasan pelanggan tergantung pada kinerja yang dimiliki oleh produk yang diterima oleh pelanggan sebagai nilai bila dibandingkan dengan harapan pelanggan pada mulanya.

Menurut Oliver (dalam Bouzaabia et al., 2013) Customer Loyalty yaitu kesetiaan yang didefinisikan sebagai komitmen yang dipegang teguh untuk membeli kembali atau berlangganan produk/layanan yang disukai secara konsisten di masa depan. Berdasarkan fakta dan teori yang ada, maka dapat dirumuskan hipotesis kerja sebagai berikut.

H1 : Diduga ada pengaruh kualitas layanan logistik terhadap kepuasan pelanggan.

$\mathrm{H} 2$ : Diduga ada pengaruh kualitas layanan logistik terhadap loyalitas pelanggan.

\section{METODE}

Penelitian ini menggunakan pendekatan kuantitatif karena penelitian ini menggunakan data berupa angka-angka hasil jawaban survei yang disebarkan kepada sampel penelitian dan dianalisis menggunakan teknik analisis statistik. Jenis penelitian pada penelitian ini adalah kausal yang meneliti sebab akibat karena memiliki pengaruh logistics service quality terhadap customer satisfaction dan customer loyalty pada PT. Matahari Department Store. Sumber data yang digunakan dalam penelitian ini adalah data primer dan data sekunder. Data primer yang diperoleh langsung dari responden dengan membuat kuesioner yang kemudian disebarkan. Sedangkan, data sekunder diperoleh secara tidak langsung melalui media perantara seperti website dan buku-buku referensi yang dikutip. Karakteristik responden yang dipilih yaitu konsumen yang pernah berbelanja online minimal satu kali dalam satu tahun terakhir melalui laman www.mataharimall.com atau mds.matahari.com. Jumlah sampel yang digunakan dalam penelitian ini sebanyak 200 responden. Teknik pengambilan sampel adalah non-probability sampling dan jenis pengambilan sampel dalam penelitian ini menggunakan convenience sampling, dan SPSS 18.0 for windows digunakan untuk menganalisis data.

\section{HASIL DAN BAHASAN}

\section{Hasil Pengolahan Data Secara Deskriptif}

Dalam penelitian ini, jumlah sampel yang digunakan dalam penelitian ini adalah sebanyak 200 responden yang sesuai dengan karakteristik populasi melalui kuesioner yang disebarkan secara online. Kemudian dilakukan klasifikasi untuk memudahkan melihat karakteristik responden dan menunjukkan bahwa $100 \%$ responden pernah berbelanja di Matahari Department Store melalui website www.mataharimall.com atau mds.mataharimall.com.

Berikut ini merupakan profil responden yang telah dikelompokkan berdasarkan jenis kelamin, usia, pekerjaan, asal daerah, tingkat pembelian dan alasan membeli di Matahari Department Store. Berdasarkan jenis kelamin, yang banyak berbelanja online di MDS adalah perempuan (64,5\%). Sementara itu kalau dilihat berdasarkan usianya, yang paling banyak memanfaatkan laman MDS adalah responden berusia $16-25 \%$ (73\%). Ditinjau dari jenis 
pekerjaan reponden, yang paling banyak berbelanja online di MDS adalah para pelajar (53,5\%). Berdasarkan asal daerah responden yang banyak menggunakan laman MDS dalam satu tahun terakhir, yang paling tinggi adalah responden dari Sumenep (28\%), diikuti responden asal Surabaya $(26,5 \%)$.

Selain itu, hasil analisis terhadap tingkat pembelian menunjukkan sebagian besar responden yang berbelanja online di Matahari Department Store dalam satu tahun terakhir yakni hanya sebanyak $1-2$ kali (57,5\%). Alasan tertinggi ketertarikan responden berbelanja online adalah "banyak diskon dan promo" (69,5\%).

\section{Logistics service quality (LSQ)}

Tabel 1

Tanggapan Responden Terkait Variabel Logistics Service Quality

\begin{tabular}{|c|c|c|c|c|}
\hline No. & Dimensi & Pernyataan & Mean & STD \\
\hline 1. & \multirow{8}{*}{$\begin{array}{l}\text { Operational } \\
\text { Logistic } \\
\text { Service Quality }\end{array}$} & $\begin{array}{l}\text { Informasi produk di Matahari } \\
\text { Department Store Online cukup jelas }\end{array}$ & 5,44 & 0,981 \\
\hline 2. & & $\begin{array}{l}\text { Produk yang dibeli dari Matahari } \\
\text { Department Store dalam kondisi baik }\end{array}$ & 5,76 & 0,975 \\
\hline 3. & & $\begin{array}{l}\text { Penjelasan untuk ketidaksesuaian } \\
\text { layanan pengiriman memuaskan }\end{array}$ & 5,55 & 0,981 \\
\hline 4. & & $\begin{array}{l}\text { Kemudahan dalam pengembalian } \\
\text { barang (return) }\end{array}$ & 5,49 & 1,017 \\
\hline 5. & & $\begin{array}{l}\text { Informasi ketersediaan barang dan } \\
\text { diskon pada produk selalu benar }\end{array}$ & 5,52 & 1,012 \\
\hline 6. & & $\begin{array}{l}\text { Ketika barang diterima dalam kondisi } \\
\text { baik }\end{array}$ & 5,69 & 0,990 \\
\hline 7. & & $\begin{array}{l}\text { Barang yang diterima sesuai dengan } \\
\text { barang yang dibeli di Matahari } \\
\text { Department Store Online }\end{array}$ & 5,80 & 0,944 \\
\hline 8. & & $\begin{array}{l}\text { Barang yang diterima sesuai dengan } \\
\text { estimasi pengiriman yang telah } \\
\text { ditentukan oleh Matahari Department } \\
\text { Store }\end{array}$ & 5,41 & 1,038 \\
\hline \multicolumn{3}{|c|}{ Rata-rata Operational Logistic Service Quality } & 5,585 & 0,9922 \\
\hline 9. & & $\begin{array}{l}\text { Karyawan Matahari Department Store } \\
\text { mampu untuk menjelaskan produk } \\
\text { secara tepat }\end{array}$ & 5,66 & 0,979 \\
\hline 10. & $\begin{array}{l}\text { Relational } \\
\quad \text { Logistic } \\
\text { Service Quality }\end{array}$ & $\begin{array}{l}\text { Karyawan Matahari Department Store } \\
\text { dapat memberikan solusi ketika } \\
\text { pelanggan mengalami kendala }\end{array}$ & 5,47 & 0,987 \\
\hline 11. & & $\begin{array}{l}\text { Karyawan Matahari Department Store } \\
\text { memberikan layanan terbaik untuk } \\
\text { mengerti kebutuhan konsumen }\end{array}$ & 5,84 & 0,991 \\
\hline \multicolumn{3}{|c|}{ Rata-rata Relational Logistic Service Quality } & 5,656 & 0,9856 \\
\hline
\end{tabular}

Tabel 1 menunjukkan tanggapan responden terkait variabel operational logistics service quality yang memiliki rata-rata mean sebesar 5,585 dan rata-rata standard deviasi sebesar 0,9922. Artinya bahwa responden setuju terhadap Operational Logistics Service Quality yang dimiliki Matahari Department Store baik dalam hal produk yang dibeli dari 
Matahari Department Store dalam kondisi baik, pelayanan ketidaksesuaian layanan pengiriman memuaskan, barang yang diterima sesuai dengan barang yang dibeli di Matahari Department Store Online.

Pada tanggapan responden terkait variabel relational logistics service quality memiliki rata-rata mean sebesar 5,656 dan rata-rata standard deviasi sebesar 0,9856. Artinya bahwa responden setuju terhadap Relational Logistics Service Quality yang dimiliki Matahari Department Store baik, yaitu karyawan Matahari Department Store dapat memberikan layanan kepada para pelanggan. Pada pernyataan "Karyawan Matahari Department Store memberikan layanan terbaik untuk mengerti kebutuhan konsumen" memiliki nilai mean tertinggi yaitu 5,84 dengan standard deviasi sebesar 0,991. Sedangkan pernyataan "Karyawan Matahari Department Store dapat memberikan solusi ketika pelanggan mengalami kendala" memiliki nilai mean terendah yaitu 5,47 dengan standard deviasi sebesar 0,987.

\section{Customer satisfaction (CS)}

Tanggapan responden terkait variabel customer satisfaction menunjukkan rata-rata mean sebesar 5,78 dan rata-rata standard deviasi sebesar 0,916. Artinya bahwa responden setuju terhadap Customer Satisfaction dalam hal layanan yang diberikan oleh Matahari Department Store dengan pernyataan "Saya merasa puas dengan kualitas produk yang dijual oleh Matahari Department Store".

\section{Customer loyalty (CL)}

Tanggapan responden terkait variabel customer loyalty menunjukkan rata-rata mean sebesar 5,39 dan rata-rata standard deviasi sebesar 1,124. Artinya bahwa responden setuju terhadap Customer Loyalty dalam hal akan selalu membeli di Matahari Department Store dengan pernyataan "Saya akan selalu membeli di Matahari Department Store".

\section{Hasil Uji Hipotesis}

Pengaruh logistics service quality terhadap customer satisfaction pada Matahari Department Store

Tabel 2

Regresi Linear Berganda Customer Satisfaction

\begin{tabular}{llcccc}
\hline No & \multicolumn{1}{c}{$\begin{array}{c}\text { Dimensi } \\
\text { /Variabel }\end{array}$} & $\begin{array}{c}\text { Unstandardized } \\
\text { Coefficients }\end{array}$ & $\beta$ & t- hitung & Sig. \\
\hline 1 & (Constant) & 0,410 & & 1,224 & 0,222 \\
2 & $\begin{array}{l}\text { Operational } \\
\text { Logistic Service } \\
\text { Quality }\end{array}$ & 0,012 & 0,400 & 5,467 & 0,000 \\
3 & Relational & 0,028 & 0,338 & 4,626 & 0,000 \\
& Logistic Service & & & & \\
& Quality & & 0,681 & \\
5 & R & & 0,464 & \\
6 & R Square & & 85,313 & \\
7 & F Hitung & & 0,000 & \\
\hline
\end{tabular}

Berdasarkan hasil model regresi linier berganda, variabel independen yang digunakan adalah operational logistic service quality dan relational logistic service quality. Data pada 
Tabel 2 menunjukkan nilai konstanta sebesar 0,410. Hal tersebut berarti bahwa ketika variabel independen pada masing-masing regresi bernilai 0, maka nilai Customer Satisfaction akan naik sebesar 0,410. Dimensi yang memiliki pengaruh tersebesar terhadap Customer Satisfaction di Matahari Department Store adalah Operational Logistic Service Quality yang memiliki nilai beta sebesar 0,400.

Nilai koefisien Korelasi ( $R$ ) sebesar 0,681 menunjukkan bahwa hubungan variable bebas penelitian yaitu operational logistic service quality dan relational logistic service quality terhadap customer satisfaction pada Matahari Department Store tergolong sangat kuat. Sementara itu, nilai koefisien determinasi menunjukkan sebesar 0,464 yang berarti bahwa dari dua dimensi yaitu operational logistic service quality dan relational logistic service quality mampu menjelaskan $46,4 \%$ variasi data dalam customer satisfaction, sedangkan sisanya $53,6 \%$ tidak dapat dijelaskan dengan logistics service quality.

Dari Tabel 2 juga ditunjukkan hasil Uji F menghasilkan F hitung 85,313 dengan nilai signifikansi sebesar 0,00 atau kurang dari 0,05 (alpha=5\%). Berdasarkan hasil ini dapat disimpulkan bahwa dimensi operational logistic service quality dan relational logistic service quality secara simultan memiliki pengaruh linier yang signifikan positif terhadap customer satisfaction pada Matahari Department Store. Maka, Logistics Service Quality memiliki pengaruh positif signifikan terhadap Customer Satisfaction.

\section{Pengaruh logistics service quality terhadap customer loyalty pada Matahari Department Store}

Tabel 3

Regresi Linear Berganda Customer Loyalty

\begin{tabular}{llcccc}
\hline No. & \multicolumn{1}{c}{$\begin{array}{c}\text { Dimensi } \\
\text { Nariabel }\end{array}$} & $\begin{array}{c}\text { Unstandardized } \\
\text { Coefficients }\end{array}$ & B & t- hitung & Sig. \\
\hline 1 & $\begin{array}{l}\text { (Constant) } \\
\text { Operational } \\
\text { Logistic Service } \\
\text { Quality }\end{array}$ & 0,498 & 0,231 & 1,781 & 0,076 \\
& 0,015 & & & 0,002 \\
3 & Relational & 0,035 & 0,508 & 7,019 & 0,000 \\
& Logistic Service & & & & \\
& Quality & & 0,690 & \\
4 & R & & 0,476 & \\
5 & R Square & & 89,482 & \\
6 & F Hitung & & 0,000 & \\
7 & Sig. F & Customer Loyalty (CL) & \\
\hline
\end{tabular}

Pada Tabel 3 ditunjukkan hasil model regresi linier berganda yang memiliki nilai konstanta sebesar 0,498 . Hal tersebut berarti bahwa ketika variabel independen pada regresi masing-masing bernilai 0, maka nilai Customer Loyalty akan naik sebesar 0,498. Dimensi yang memiliki pengaruh terbesar terhadap Customer Loyalty di Matahari Department Store adalah Relational Logistic Service Quality yang memiliki nilai beta sebesar 0,508.

Nilai koefisien Korelasi (R) sebesar 0,690 menunjukkan bahwa hubungan variable bebas penelitian yaitu operational logistic service quality dan relational logistic service quality terhadap customer loyalty pada Matahari Department Store tergolong sangat kuat. Berikutnya, nilai koefisien determinasi adalah 0,476 yang berarti bahwa dari dua dimensi yaitu operational logistic service quality dan relational logistic service quality mampu menjelaskan $47,6 \%$ variasi 
data dalam customer satisfaction, sedangkan sisanya $52,4 \%$ tidak dapat dijelaskan dengan logistics service quality.

Tabel 3 juga menunjukkan hasil Uji $\mathrm{F}$ yang menghasilkan $\mathrm{F}$ hitung 89,482 dengan nilai signifikansi sebesar 0,00 atau kurang dari 0,05 (alpha=5\%). Berdasarkan hasil ini dapat disimpulkan bahwa dimensi operational logistic service quality dan relational logistic service quality secara simultan memiliki pengaruh linier yang signifikan positif terhadap customer loyalty pada Matahari Department Store. Oleh karena itu dapat dikatakan bahwa Logistics Service Quality memiliki pengaruh positif signifikan terhadap Customer Loyalty.

\section{SIMPULAN}

Dari hasil penelitian ini, implikasi secara teoretis maupun praktis yang diberikan penulis adalah sebagai berikut.

\section{Implikasi Teoretis}

Penelitian ini mendukung model penelitian yang dikemukakan oleh Bouzaabia et al (2013) yang di dalamnya terdapat dua dimensi yaitu operational logistic (information quality, order quality, ordering procedures, order discrepancy handling, ordering release quantities, order condition, order accuracy, dan timeliness) dan relational logistic (assurance, responsiveness dan carring). Dimensi operational logistic dan relational logistic memiliki pengaruh signifikan terhadap kepuasan pelanggan (customer satisfaction) dan loyalitas pelanggan (customer loyalty). Hasil ini juga memperkuat penelitian Bouzaabia et al. yang mendapatkan hasil yang sama terkait dengan pengaruh kualitas layanan logistik (logistics service quality) berpengaruh terhadap kepuasan pelanggan (customer satisfaction) dan loyalitas pelanggan (customer loyalty).

\section{Implikasi Praktis}

Secara keseluruhan Logistics Service Quality yang diberikan Matahari Department Store tergolong baik karena total mean pada pengujian statistic $>$ dari 5. Hal ini menyebabkan pelanggan Matahari Department Store merasakan kepuasan dan loyalitas. Hasil penelitian ini secara keseluruhan menunjukan Logistics Service Quality berpengaruh signifikan positif terhadap Customer Satisfaction dan Customer Loyalty. Hal ini dikarenakan kinerja Logistics Service Quality pada Matahari Department Store telah memenuhi harapan pelanggannya, sehingga pelanggan menjadi puas dan loyal terhadap Logistics Service Quality pada Matahari Department Store.

Selain itu, beberapa rekomendasi dari hasil penelitian ini yang diharapkan dapat menjadi masukan bagi Matahari Department Store dan bagi peneliti selanjutnya adalah sebagai berikut.

Hasil penelitian menunjukkan nilai rata-rata dimensi operational logistic service quality pada item timeliness mendapat penilaian yang kurang dibandingkan sepuluh dimensi lainnya. Hal ini dikarenakan layanan pengiriman pada Matahari Department Store mengalami keterlambatan pengiriman pesanan yang disebabkan kerena pesanan dari para pelanggan melebihi kapasitas pengiriman. Akibatnya, barang yang dikirim kepada pelanggan tidak diterima sesuai dengan estimasi yang telah ditentukan oleh Matahari Department Store. Oleh karena itu, Matahari Department Store harus menjalin kerja sama dengan jasa pengiriman yang ada di Indonesia agar pengiriman barang dapat sampai sesuai dengan estimasi pengiriman yang telah ditentukan oleh pihak Matahari.

Penelitian ini tidak terlepas dari keterbatasan penelitian yang dilakukan hanya pada retail Matahari Department Store saja. Oleh karena itu, keterbatasan penelitian ini dapat membuka peluang untuk peneliti selanjutnya di masa yang akan datang. Penelitian ini hanya dilakukan untuk menilai kualitas layanan logistik pada retail Matahari Department Store. 
Penelitian selanjutnya diharapkan dapat menilai kualitas layanan logistik pada retail-retail lainnya.

\section{PUSTAKA ACUAN}

Bachdar, S 2017, 2 Maret, Mengapa ada dua nama Matahari di dunia e-commerce? Diunduh pada tanggal 9 April 2018 dari https://marketeers.com/mengapa-ada-dua-namamatahari-di-dunia-e-commerce/

Belanja Online Marak, PDB Sektor Logistik Tumbuh, 2018, 22 Februari, diunduh pada 30 Mei 2018 dari https://databoks.katadata.co.id/datapublish/2018/02/22/belanja-onlinemarak-pdb-sektor-logistik-tumbuh

Bienstock, CC, Mentzer, JT \& Bird, MM 1997, 'Measuring physical distribution service quality', Journal of the Academy of Marketing Science, 25(1), 31-44.

Bouzaabia R, Bouzaabia O \& Alexandru, C 2013, 'Retail logistics service quality: A cross culture survey on customer perception', International Journal of Retail \& Distribution Management, 41(8),627-647.

Gil-Saura, I \&Ruiz-Molina, ME 2011, 'Logistics service quality and buyer-customer relationships: The moderating role of technology in B2B and B2C contexts', The Service Industries Journal, 31(6), 1109-1123.

Hidayat, A 2018, 26 Juli, Indonesia naik 17 tingkat dalam indeks logistik dunia 2018, diunduh pada 19 September 2018 dari https://industri.kontan.co.id/news/indonesia-naik-17tingkat-dalam-indeks-logistik-dunia-2018

Kotler, P \& Keller, LK 2016, Marketing management, 15 th ed., Pearson.

Maulana, R \& Pradana, RS 2018, 9 Mei, Industri kian menggeliat, diunduh pada 19 September 2018 dari http://www.ali.web.id/web2/news_detail.php?id=1478

Mentzer, JT, Flint, DJ \& Hult, GTM 2001, 'Logistics service quality as a segment customized process', Journal of Marketing Channels, 65(4), 82-104.

\section{BIBLIOGRAFI}

Aksoy, L, Buoye, A, Aksoy, P, Larivie're, B \& Keiningham, TL 2013, 'A cross-national investigation of the satisfaction and loyalty linkage for mobile telecommunications services across eight countries, Journal of Interactive Marketing, 27, 74-82.

Christianus, S 2010, Seri Belajar Kilat SPSS 18, Andi dan Elcom, Yogyakarta.

Gil-Saura, I, Ruiz-Molina, ME \& Servera-France's, D 2008a, 'Logistic service quality and technology: a comparison between supplier retailer and retailer-consumer relationships', The International Review of Retail, Distribution and Consumer Research, 18(5), 495-510.

Gil-Saura, I, Servera-France's, D, Berenguer-Contri, G \& Fuentes Blasco, M 2008b, 'Logistics service quality: A new way to loyalty', Industrial Management and Data Systems, 108(5), 650-668.

Heim, GR \& Sinha, KK 2001, 'Operational drivers of customer loyalty in electronic retailing: An empirical analysis of electronic food retailers', Manufacturing and Service Operations Management, 3(3), 264-271.

Malhotra, NK, Ulgado, FM, Agarwal, J, Shainesh, G \& Wu, L 2005, 'Dimensions of service quality in developed and developing economies: Multi-country cross-cultural comparisons', International Marketing Review, 22(3), 256-278.

Rafiq, M \& Jaafar, HS 2007, 'Measuring customers' perceptions of logistics service quality of 3PL service', Journal of Business Logistics, 28(2), 159. 
Ramanathan, R 2010), 'The moderating roles of risk and efficiency on the relationship between logistics performance and customer loyalty in e-commerce', Transportation Research, 46, 950-962.

Sujianto, AE 2009, Aplikasi statistik dengan SPSS 16.0, Prestasi Pustaka Publisher, Jakarta. Supranto, J 2008, Statistik teori dan aplikasi, edisi ketujuh, Erlangga Publisher, Jakarta. 